\title{
Gut It Out: Laxative Abuse Mimicking Distal Renal Tubular Acidosis
}

\author{
Marius Sidler ${ }^{\mathrm{a}}$ Nilufar Mohebbi ${ }^{\mathrm{b}} \quad$ Ewout J. Hoorn ${ }^{\mathrm{c}}$ Carsten A. Wagner ${ }^{\mathrm{a}}$ \\ anstitute of Physiology, University of Zurich, Zurich, Switzerland; ${ }^{\mathrm{b}}$ Division of Nephrology, \\ University Hospital Zurich, Zurich, Switzerland; ${ }^{\mathrm{c}}$ Division of Nephrology and \\ Transplantation, Department of Internal Medicine, Erasmus MC, University Medical Center \\ Rotterdam, Rotterdam, The Netherlands
}

\section{Keywords}

Distal renal tubular acidosis · Laxative abuse

\begin{abstract}
Background: Distal renal tubular acidosis (dRTA) can be inherited or acquired. Case Presentation: Here, we describe the case of a 45 -year-old female patient with non-anion gap metabolic acidosis, hypokalemia, and alkaline urine. She had a history of rheumatoid arthritis and kidney stones and failed to acidify urine upon the fludrocortisone and furosemide test. Therefore, the diagnosis of dRTA secondary to an autoimmune disease was made. A kidney biopsy was examined for markers of acid-secretory intercalated cells. Surprisingly, no obvious difference in the relative number of acid-secretory intercalated cells or in the distribution of major proteins involved in acid secretion was found. Furthermore, increasing doses of potassium citrate failed to correct the hypokalemia and acidosis. Since these findings were rather atypical for autoimmune dRTA, alternative causes of her hypokalemia and metabolic acidosis were sought. The patient was found to chronically consume laxatives, which can also cause kidney stones and may result in a false-positive urinary acidification test. Conclusion: Chronic laxative abuse may mimic dRTA and should therefore be considered in unexplained hypokalemia with non-anion gap metabolic acidosis.

(c) 2019 The Author(s)

Published by S. Karger AG, Basel
\end{abstract}

Ewout J. Hoorn and Carsten A. Wagner share last authorship. 


\section{Kidney \\ Blood Pressure \\ Research}

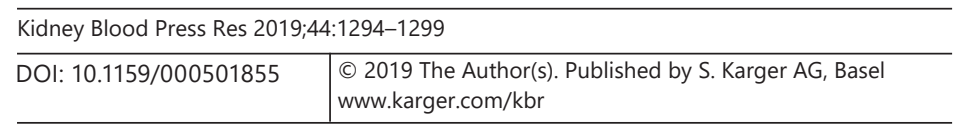

Sidler et al.: Gut It Out: Laxative Abuse Mimicking Distal Renal Tubular Acidosis

\section{Introduction}

Distal renal tubular acidosis (dRTA), the inability to appropriately acidify urine in the face of metabolic acidosis or upon an acid challenge, can be inherited or acquired. The disease is characterized by non-anion gap metabolic acidosis and alkaline urine and is often accompanied by hypokalemia. Chronically, kidney stones or nephrocalcinosis are often found [1].

Inherited forms of dRTA are rare and caused by mutations in either the SLC4A1 (AE1) anion exchanger, the B1 (ATP6V1B1) or a4 (ATP6V0a4) subunits of the V-type $\mathrm{H}^{+}$-ATPase, or the transcription factor FOXI1 $[2,3]$. These forms of dRTA are usually diagnosed during the first years of life and can be associated with sensorineural deafness with mutations in ATP6V1B1, ATP6V0a4, and FOXI1.

In contrast, acquired forms of dRTA are more common and can be caused by a variety of conditions including autoimmune diseases such as Sjögren's syndrome, rheumatoid arthritis, and systemic lupus erythematosus, by nephrocalcinosis and as a side effect of various drugs or toxins such as toluene, amphotericin $B$, or lithium $[1,4,5]$.

Here, we describe the case of a patient with alkaline urine, hypokalemia, non-anion gap metabolic acidosis, and a positive urinary acidification test initially diagnosed as dRTA. However, her kidney biopsy did not reveal any obvious alterations in key proteins of the acid-secretory intercalated cells. Further investigation revealed chronic abuse of laxatives mimicking dRTA.

\section{Clinical Synopsis of the Case}

A 45-year-old patient was referred from another hospital because of unexplained severe hypokalemia (plasma potassium frequently $<2.5 \mathrm{mmol} / \mathrm{L}$ ). She had a previous history of rheumatoid arthritis with autoantibodies against cyclic citrullinated peptides for which she had used hydroxychloroquine, leflunomide, methotrexate, and sulfasalazine. At the time of referral, she was only using glucocorticoids (prednisone $5 \mathrm{mg}$ once daily).

Her hypokalemia was characterized by renal potassium loss (urine potassium $29 \mathrm{mmol} / \mathrm{L}$ at the time of hypokalemia), normal blood pressure, and non-anion gap metabolic acidosis (plasma sodium $139 \mathrm{mmol} / \mathrm{L}$, chloride $111 \mathrm{mmol} / \mathrm{L}$, and bicarbonate $16 \mathrm{mmol} / \mathrm{L}$ ) with a consistently high urine pH (7 or 8). She did not have nephrocalcinosis, but she did have recurrent kidney stones (stone composition unknown). Therefore, a presumptive diagnosis of dRTA was made, possibly secondary to rheumatoid arthritis [6].

A urinary acidification test was performed with fludrocortisone and furosemide, during which she failed to lower her urinary $\mathrm{pH}$ below 5.3 (urine $\mathrm{pH}$ at the start: 6.5; after $1 \mathrm{~h}$ : 6.0; after $4 \mathrm{~h}$ : 6.0; urine $\mathrm{pH}$ was measured immediately after collection). Treatment with potassium citrate was started (liquid potassium citrate containing $133 \mathrm{mmol}$ potassium and $44 \mathrm{mmol}$ citrate per day). Because she had a decrease in estimated glomerular filtration rate to $40 \mathrm{~mL} /$ $\mathrm{min} / 1.73 \mathrm{~m}^{2}$ with erythrocyturia and proteinuria ( $0.8 \mathrm{~g} /$ day), she underwent a kidney biopsy.

The biopsy contained 27 glomeruli, of which none showed global sclerosis. The glomerular capillaries, glomerular basement membrane, and mesangium all appeared normal. Immunofluorescence did not show any deposits for IgG, IgA, IgM, C3c, C1q, kappa, or lambda. Electron microscopy showed a normal aspect of the podocytes, endothelial cells, and glomerular basement membrane and did not identify any electron-dense deposits. In the tubulointerstitium, no inflammatory cell infiltrate was observed. To further investigate a possible autoimmune origin of dRTA, markers for principal and intercalated cells and acid-base transporters were analyzed by immunofluorescence, showing normal expression of AE1, AQP2, and the $\mathrm{H}^{+}$-ATPase subunits B1 and a4 (Fig. 1; online suppl. methods; for all online suppl. material, see www.karger.com/doi/10.1159/000501855). 
Kidney

Blood Pressure

Research
Kidney Blood Press Res 2019;44:1294-1299 DOI: $10.1159 / 000501855$

(C) 2019 The Author(s). Published by S. Karger AG, Base www.karger.com/kbr

Sidler et al.: Gut It Out: Laxative Abuse Mimicking Distal Renal Tubular Acidosis
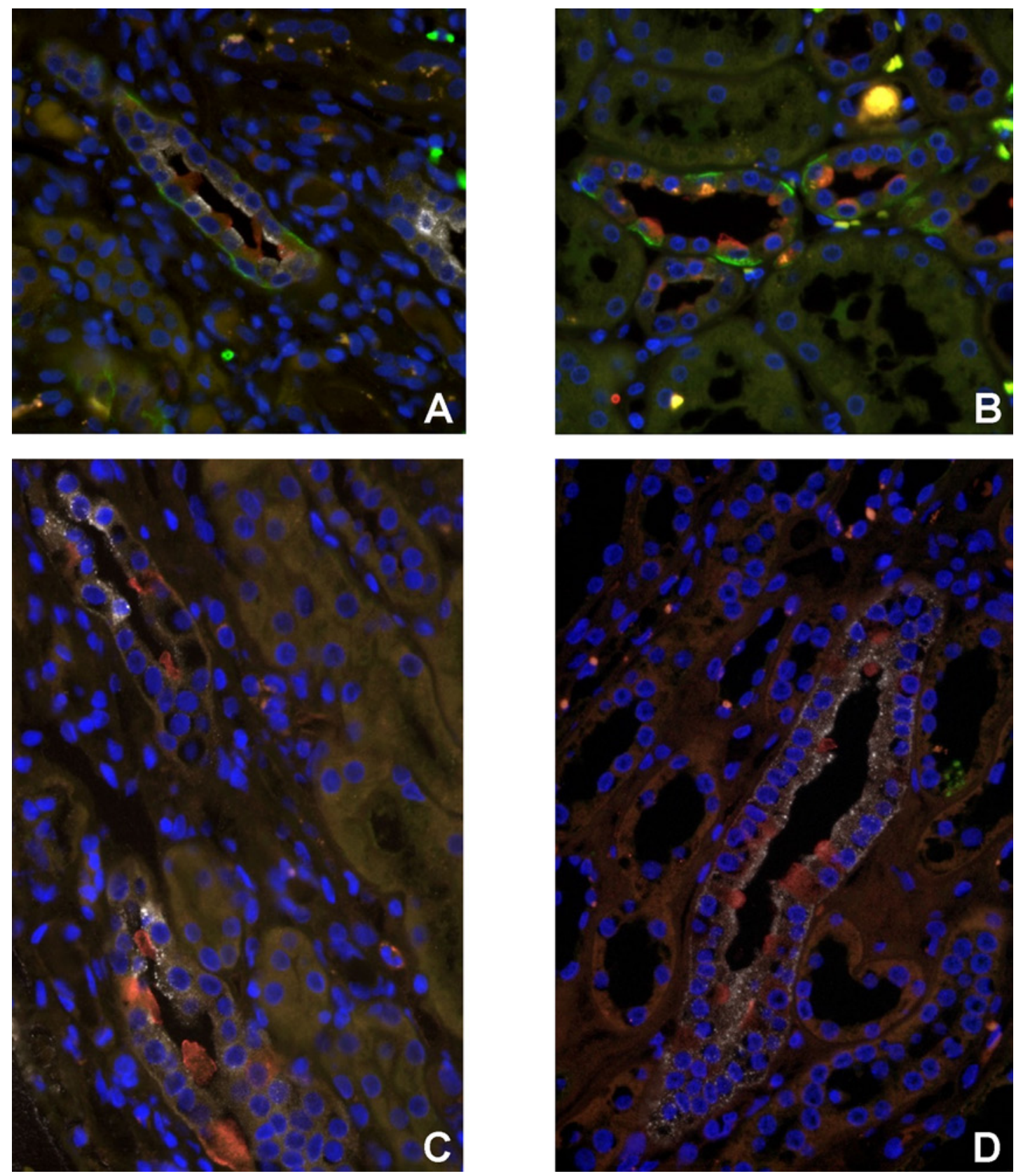

Fig. 1. Kidney biopsies from the patient $(\mathbf{A}, \mathbf{C})$ and control biopsies from 4 different healthy kidneys (B, D) were stained with antibodies against the $\mathrm{B} 1 \mathrm{H}^{+}$-ATPase subunit (red), the anion exchanger AE1 (green), and AQP2 (white) (A, B) or against the a4 $\mathrm{H}^{+}$-ATPase subunit (red) and AQP2 (white) (C, D). The nuclei were stained blue with DAPI. A similar relative number of cells stained for the B1 subunit and for the AE1 exchanger in the patients' and the controls' kidney biopsies. Similarly, the a4 subunit was stained similarly in the patients' and controls' kidney biopsies. Original magnification, $\times 400$.

In the subsequent course in the outpatient clinic, the patient repeatedly presented with hypokalemia and acidosis despite increasing doses of potassium citrate. This forced us to reanalyze the case. The biochemical picture during one of these episodes (plasma potassium $2.9 \mathrm{mmol} / \mathrm{L}$ and bicarbonate $16.9 \mathrm{mmol} / \mathrm{L}$ ) now showed lower urinary potassium (17 mmol/L) with a slightly negative urine anion gap (urine sodium + potas- 


\section{Kidney \\ Blood Pressure \\ Research}

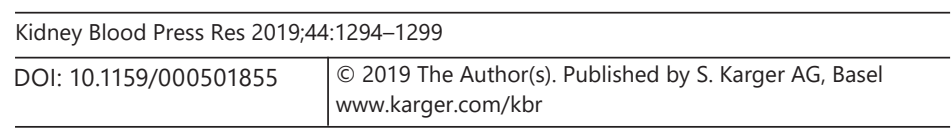

Sidler et al.: Gut It Out: Laxative Abuse Mimicking Distal Renal Tubular Acidosis

sium - chloride $=66+17-89=-6 \mathrm{mEq})$, a normal estimated $\mathrm{NH}_{4}{ }^{+}$level $(54 \mathrm{mmol} / \mathrm{L}$ by calculation of the urinary osmol gap), and a urine sodium-to-chloride ratio $<1$. This suggested a self-induced cause of hypokalemic metabolic acidosis, e.g., due to laxative abuse. Indeed, her urine test resulted positive for emodin, bisacodyl, and rhein. A urinary screen for diuretics was negative.

\section{Discussion}

We reported a case of non-anion gap metabolic acidosis with hypokalemia and impaired urinary acidification during a fludrocortisone and furosemide test. The differential diagnosis of non-anion gap metabolic acidosis includes renal and extrarenal causes $[1,4]$. Renal causes are impaired kidney function as well as classic dRTA (type I dRTA). Abnormal aldosterone levels or signaling would be associated with the hyperkalemic variant of type IV RTA. However, our patient was clearly and repetitively hypokalemic. The patient's history of rheumatoid arthritis suggested a possible renal involvement. dRTA is observed in a substantial percentage of patients with autoimmune diseases such as lupus erythematosus, Sjögren's syndrome, or rheumatoid arthritis, presumably due to autoantibodies directed also against structures of acid-secretory intercalated cells [5-9]. Indeed, a urinary acidification test (fludrocortisone and furosemide) [10] demonstrated a reduced ability to acidify urine, which is consistent with dRTA. However, a kidney biopsy stained for markers of acid-secretory intercalated cells and principal cells showed a normal relative abundance of acid-secretory cells and no obvious alteration in the distribution of proton pumps in these cells. This is in contrast to previous reports where kidney biopsies from patients with dRTA due to autoimmune disease had shown an absence of markers of acid-secretory intercalated cells [5, 11]. Furthermore, the kidney biopsy did not show tubulointerstitial nephritis, which is typically found in patients with autoimmune dRTA.

The lack of improvement of hypokalemia and metabolic acidosis with $\mathrm{K}^{+}$citrate supplements led to a reevaluation of the patient, which revealed a chronic abuse of laxatives. Also, the urinary ammonium excretion estimated from the urine osmol gap now suggested an extrarenal cause of the metabolic acidosis and hypokalemia due to intestinal loss of $\mathrm{K}^{+}$and $\mathrm{HCO}_{3}{ }^{-}$. Chronic use of laxatives is known to cause wasting of both ions [12]. Hypokalemia per se is expected to rather stimulate renal acid excretion and bicarbonate synthesis, leading to metabolic alkalosis [13-15].

In our patient, intestinal losses of $\mathrm{HCO}_{3}{ }^{-}$may have exceeded the renal capacity to compensate these losses. The renal losses of $\mathrm{K}^{+}$observed during the earlier visits may in part be explained by glucocorticoid treatment [16], secondary aldosteronism due to hypovolemia or vomiting, or surreptitious use of diuretics (her urine was only screened once for diuretic use). The reason for the abnormal urinary acidification test results remains elusive, but falsepositive results have previously been reported for the furosemide and fludrocortisone test $[8,17]$. In general, the following causes can lead to a false-positive urinary acidification test. First, concurrent hypovolemia may increase sodium reabsorption in the proximal tubule and therefore blunt the response to furosemide and fludrocortisone in the distal nephron. Second, bacteriuria may artifactually increase the urine $\mathrm{pH}$ (some bacteria can split urea into ammonia). Third, the urine $\mathrm{pH}$ can increase if carbon dioxide diffuses, and the urine $\mathrm{pH}$ should therefore be measured immediately or the urine should be collected under mineral oil. Therefore, if available, urine titratable acidity and ammonium are superior to urine $\mathrm{pH}$ in the evaluation of dRTA [18-20].

Regarding our patient, one possible explanation is that hypovolemia increased reabsorption by the proximal tubule and blunted the response of furosemide and fludrocortisone 
Table 1. Similarities and differences between distal renal tubular acidosis and laxative abuse

\begin{tabular}{lll}
\hline & Distal renal tubular acidosis & Chronic laxative abuse \\
\hline Non-anion gap metabolic acidosis & Yes & Yes \\
Hypokalemia & Yes & Yes \\
Kidney stones & Yes & Possible \\
Nephrocalcinosis & Yes & No \\
Impaired urinary acidification & Yes & Possible \\
Urinary ammonium excretion & Reduced & Increased \\
Urinary sodium-to-chloride ratio & Normal $(1)$ & Reduced $(<1)$ \\
\hline
\end{tabular}

in the distal nephron. Chronic laxative abuse can also cause kidney stones, including calcium oxalate or ammonium urate stones [21]. Thus, chronic laxative abuse may mimic dRTA (Table 1). Recently, the urinary sodium-to-chloride ratio was reported as a useful parameter to differentiate the various causes of chronic hypokalemia, including dRTA and laxative abuse [12]. In dRTA, the urinary sodium-to-chloride ratio is typically close to 1 , whereas laxative abuse will reduce this ratio due to volume depletion (lower urinary sodium excretion) and metabolic acidosis (higher urinary chloride excretion).

In summary, chronic abuse of laxatives causes intestinal losses of $\mathrm{K}^{+}$and $\mathrm{HCO}_{3}{ }^{-}$and should be considered as a differential diagnosis in patients with non-anion gap metabolic acidosis even in the presence of apparently impaired urinary acidification. Urinary ammonium excretion (estimated or measured) and the urinary sodium-to-chloride ratio may help to differentiate dRTA from chronic laxative abuse.

\section{Statement of Ethics}

The patient gave written informed consent for the biopsy, the examination, and the publication of her case report. Control biopsies were obtained and examined under a protocol approved by the Ethics Committee of the canton of Zurich (No. KEK-Zh-Nr. 20120312).

\section{Disclosure Statement}

All authors declare no conflicts of interest.

\section{Funding Sources}

This study was in part supported by a grant from the Swiss National Science Foundation (31003A_176125).

\section{Author Contributions}

M.S. and C.A.W. performed experiments; E.J.H. saw the patient and collected clinical information; N.M., E.J.H., and C.A.W. planned and analyzed experiments and clinical data; M.S., E.J.H., and C.A.W. wrote the manuscript; and all authors read and approved the manuscript. 


\section{References}

1 Dhondup T, Qian Q. Acid-Base and Electrolyte Disorders in Patients with and without Chronic Kidney Disease: An Update. Kidney Dis (Basel). 2017 Dec;3(4):136-48.

2 Enerbäck S, Nilsson D, Edwards N, Heglind M, Alkanderi S, Ashton E, et al. Acidosis and Deafness in Patients with Recessive Mutations in FOXI1. J Am Soc Nephrol. 2018 Mar;29(3):1041-8.

3 Mohebbi N, Wagner CA. Pathophysiology, diagnosis and treatment of inherited distal renal tubular acidosis. J Nephrol. 2018 Aug;31(4):511-22.

4 Pham AQ, Xu LH, Moe OW. Drug-Induced Metabolic Acidosis. F1000 Res. 2015 Dec;4:4.

5 van den Wildenberg MJ, Hoorn EJ, Mohebbi N, Wagner CA, Woittiez AJ, de Vries PA, et al. Distal renal tubular acidosis with multiorgan autoimmunity: a case report. Am J Kidney Dis. 2015 Apr;65(4):607-10.

6 Caruana RJ, Buckalew VM Jr. The syndrome of distal (type 1) renal tubular acidosis. Clinical and laboratory findings in 58 cases. Medicine (Baltimore). 1988 Mar;67(2):84-99.

7 Caruana RJ, Barish CF, Buckalew VM Jr. Complete distal renal tubular acidosis in systemic lupus: clinical and laboratory findings. Am J Kidney Dis. 1985 Jul;6(1):59-63.

8 Both T, Hoorn EJ, Zietse R, van Laar JA, Dalm VA, Brkic Z, et al. Prevalence of distal renal tubular acidosis in primary Sjögren's syndrome. Rheumatology (Oxford). 2015 May;54(5):933-9.

9 Pertovaara M, Korpela M, Kouri T, Pasternack A. The occurrence of renal involvement in primary Sjögren's syndrome: a study of 78 patients. Rheumatology (Oxford). 1999 Nov;38(11):1113-20.

10 Walsh SB, Shirley DG, Wrong OM, Unwin RJ. Urinary acidification assessed by simultaneous furosemide and fludrocortisone treatment: an alternative to ammonium chloride. Kidney Int. 2007 Jun;71(12):1310-6.

11 Walsh S, Turner CM, Toye A, Wagner C, Jaeger P, Laing C, et al. Immunohistochemical comparison of a case of inherited distal renal tubular acidosis (with a unique AE1 mutation) with an acquired case secondary to autoimmune disease. Nephrol Dial Transplant. 2007 Mar;22(3):807-12.

12 Wu KL, Cheng CJ, Sung CC, Tseng MH, Hsu YJ, Yang SS, et al. Identification of the Causes for Chronic Hypokalemia: Importance of Urinary Sodium and Chloride Excretion. Am J Med. 2017 Jul;130(7):846-55.

13 Silver RB, Breton S, Brown D. Potassium depletion increases proton pump (H(+)-ATPase) activity in intercalated cells of cortical collecting duct. Am J Physiol Renal Physiol. 2000 Jul;279(1):F195-202.

14 Bailey MA, Fletcher RM, Woodrow DF, Unwin RJ, Walter SJ. Upregulation of H+-ATPase in the distal nephron during potassium depletion: structural and functional evidence. Am J Physiol. 1998 Dec;275(6):F878-84.

15 Lee Hamm L, Hering-Smith KS, Nakhoul NL. Acid-base and potassium homeostasis. Semin Nephrol. 2013 May; 33(3):257-64.

16 Ben Salem C, Hmouda H, Bouraoui K. Drug-induced hypokalaemia. Curr Drug Saf. 2009 Jan;4(1):55-61.

17 Viljoen A, Norden AG, Karet FE. Replacing the short ammonium chloride test. Kidney Int. 2007 Nov; 72(9): 1163; author reply 1164.

18 Wrong O. Distal renal tubular acidosis: the value of urinary pH, PCO2 and NH4+ measurements. Pediatr Nephrol. 1991 Mar;5(2):249-55.

19 Carlisle EJ, Donnelly SM, Halperin ML. Renal tubular acidosis (RTA): recognize the ammonium defect and pHorget the urine pH. Pediatr Nephrol. 1991 Mar;5(2):242-8.

20 Santos F, Ordóñez FA, Claramunt-Taberner D, Gil-Peña H. Clinical and laboratory approaches in the diagnosis of renal tubular acidosis. Pediatr Nephrol. 2015 Dec;30(12):2099-107.

21 Leaf DE, Bukberg PR, Goldfarb DS. Laxative abuse, eating disorders, and kidney stones: a case report and review of the literature. Am J Kidney Dis. 2012 Aug;60(2):295-8. 